\title{
Clímaco Dias
}

Professor do Departamento de Geografia e doutor pelo Programa de Pós-Graduação em Geografia (POSGEO) da Universidade Federal da Bahia (UFBA)

climacodias@gmail.com

\section{Resistências dos pobres nos bairros populares de Salvador e o Período Popular da História}

\begin{abstract}
Resumo
$\mathrm{O}$ artigo aqui apresentado baseia-se em uma pesquisa que fiz para a minha tese de doutorado, em 2017, que buscou uma empiria para a proposição de Milton Santos a respeito do período popular ou demográfico da história, através da qual argumenta que sua existência se dá como a oposição ao período da globalização atual apoiado no meio técnico-científico-informacional. O Período Popular estaria ancorado, principalmente, na comunicação dos pobres das grandes cidades dos países do Terceiro Mundo. A proposição que fiz, na pesquisa citada, é que uma das formas de comunicação a se cristalizar são as relações de vizinhança e parentesco dos pobres em bairros populares de Salvador e, para isso, identifiquei dezenas de práticas e trago algumas no presente artigo. Desenvolvi um conceito territorial de pobre, o qual não está vinculado estritamente à renda familiar, mas incorpora elementos de condição cidadã. Os conceitos de bairro popular e de aglomerados de bairros também são algo que assumo a autoria, embora reconheça as fortes influências de autores seminais nessas formulações. Outra questão trazida é que, para se entender a existência de dois períodos históricos, em uma mesma temporalidade, é preciso incorporar a geografia como instância da análise social.
\end{abstract}

Palavras-chave: Período Popular da História, Globalização, Comunicação dos pobres em Salvador. 


\begin{abstract}
RESISTANCE OF THE POOR WITHIN SALVADOR'S POPULAR NEIGHBORHOODS AND POPULAR HISTORIC ERA

The following paper is based on the research conducted for my PhD final thesis, in 2017, where I pursued an empiric exercise for Milton Santos' proposition of a popular or demographic historic era, in which he argues that its existence presents itself as an opposition to the current globalization era supported by the technical-scientific-informational medium and that this popular era in grounded in the communication disenfranchised of Third World major cities. The statement I have maid, in the mentioned thesis, is that one of the ways that this communication crystallizes itself is through neighborhood relations and kinship of poor people at Salvador de Bahia's popular districts and, therefore, I have identified dozens of these practices and exposed some of them in this paper. I have developed a poor people territorial concept, by which it is not only strictly binded to family income but incorporates elements of citizenship condition. The concept of popular neighborhood is also something that I assume authorship, while recognizing strong influences from seminal authors to these formulations. Another issue raised in this written piece is that to understand the existence of two historical eras, in the same time lapse, it is necessary to incorporate geography as an instance of social analysis.
\end{abstract}

Key-words: Popular historic era, Globalization, Communication of the poor in Salvador.

\title{
1. Um período, o pobre e o bairro
}

O Período Popular da História é o desaguadouro do esforço teórico de Milton Santos e é uma proposição utópica fundada em sua teoria de que o meio técnico-cientifico-informacional (SANTOS, 1996) é a expressão da globalização e que atua nos lugares de forma verticalizada. Desde já, chama-se atenção para o fato de que o autor citado preferia usar o vocábulo "popular" e optava pelo uso de Período Demográfico da História. Porém, aqui, a primeira proposição coloca o pobre de forma explícita na articulação com a empiria realizada em bairros populares de Salvador-Bahia por Dias (2017), portanto, assume-se neste artigo a denominação de Período Popular da História.

A globalização tem fluxos homogeneizantes, mas exclui a grande maioria da sociedade de sua totalidade. Produz uma quantidade imensa de excluídos que, por viverem no reino da necessidade e usarem de forma bastante diferenciada o território, criam maneiras de sobrevivência que 
também funcionam como resistências ao meio técnico-científico-informacional e, somando-se à sua grande capacidade de comunicação motivada pela densificação, os pobres criam possibilidades de alternativas de uma nova ordem global a partir das suas vivências cotidianas (SANTOS, 1999).

O Período Popular da História, segundo Milton Santos, se insere no grupo de formulações teóricas utópicas, mesmo que algumas sejam díspares, a exemplo da revolução do proletariado instituindo o comunismo em Karl Marx e Friedrich Engels (1999), a teoria da ação comunicativa de Habermas (2011), o autonomismo de Castoriadis (1987), o anarquismo de Reclus (2010, 2011), sendo que o existencialismo de Sartre (1970) se espraia por toda a construção do pensamento miltoniano. Só que o Período Popular da História difere das utopias referenciadas, sendo uma genuína utopia geográfica, que nasce a partir da tensão que Milton Santos estabelece com as ciências sociais, ao fazer a crítica das suas incompletudes na análise social, pela ausência do espaço geográfico como uma instância dessas análises. Para Santos, tal exigência torna-se maior com o período atual da globalização, que acentua sobremaneira o papel do espaço geográfico, na medida em que as horizontalidades do lugar, na relação dialética com as verticalidades dos fluxos do meio técnico-cientifico-informacional, absorvem muitas normas globais, mas resistem a outras tantas pela incapacidade de o território incorporá-las em sua plenitude.

Em Marx, a centralidade das transformações é concentrada no proletariado e não apresenta contornos bem definidos. O autor propõe então que uma parte expressiva do proletariado que teria ações contrarrevolucionárias, o lumpemproletariado, por sua inserção no universo da produção, não teria consciência de classe. Portanto, a formulação conceitual de Marx é umbilicalmente vinculada à esfera econômica capitalista, o que mais tarde favorece Lenin a definir o operariado industrial como vanguarda por desempenhar uma atividade no setor de ponta do capitalismo. E a história mostrou que os processos transformadores em muitos países seguiram muito mais as especificidades do território usado do que o desenvolvimento das forças produtivas do capitalismo.

Milton Santos desenvolve uma teoria que define o espaço geográfico como a reunião dos sistemas de objetos e sistemas de ações (SANTOS, 1999) e, a partir do próprio pressuposto, propõe que seja, dentro da análise 
dialética, uma das instâncias da análise social, principalmente depois que a globalização econômica começa a privilegiar os lugares em busca de lucros; mas, ao mesmo tempo, tais lugares, na medida em que passam a ser objetos da cobiça de lucros, são espaços de resistência, sobretudo nas metrópoles dos países do Terceiro Mundo. Ocorre que, pela grande densificação dos pobres e por sua comunicação escapar do controle das verticalidades, e por viverem no reino da necessidade, essa comunicação se processa como uma imposição da sobrevivência.

Em pesquisa que desenvolvi (DIAS, 2017), busquei aplicar a teoria referenciada em bairros populares da cidade de Salvador e, ancorado na formulação que Santos (2009) faz no livro Pobreza Urbana, postulei que o pobre, na teoria social, é muito definido pela renda sem que seja considerado sua condição geográfica, a exemplo do seu local de moradia, como é o caso das grandes cidades brasileiras nas quais ser pobre é muito mais caracterizado pelo lugar que habita do que exclusivamente pela renda. Conceituo pobre da seguinte forma:

O pobre é o indivíduo que tem, na maioria dos casos, moradias diferenciadas dos outros grupos sociais que habitam em áreas planejadas da cidade, com atendimento completo pelo Estado e pelas corporações prestadoras destes serviços, não tem a completude das técnicas do meio técnico-cientifico-informacional, mora em áreas com maiores índices de violência contra a pessoa e violência policial, não tem um atendimento pleno dos serviços essenciais, a exemplo de água encanada, luz, esgoto, coleta de lixo e transporte público, tem rendas quase sempre abaixo dos setores médios, não consome serviços de lazer comumente usufruídos pelos setores médios, estabelece relações de parentesco e vizinhança diferenciadas pela intensidade dos demais grupos e classes sociais, pratica relações comerciais de forma muito acentuada com e no circuito inferior da economia, tem vínculos e práticas religiosas muito mais significativos do que outro segmento social, tem terrenos e edificações sem titulação através do Estado e, na maioria das vezes, é um negro ou afrodescendente. E essas características estão estreitamente vinculadas às práticas sociais que estabelecem uma estreita relação dialética com a materialidade onde os pobres habitam, o bairro popular e o uso do seu território (DIAS, 2017, p. 44).

Outros aspectos que podem ser acrescentados à tentativa de formulação do conceito levam em consideração questões como o fato de que as populações dos bairros populares não gozam nem das garantias constitucionais mínimas. Nos conflitos entre polícia, milícias e tráfico, residências de pessoas são invadidas por traficantes e milicianos e mesmo a polícia, que é a representação do Estado, em qualquer refrega com os 
traficantes, viola habitações sem mandados judiciais, faz revistas abusivas, inicia tiroteios na via pública e, mesmo sem qualquer ameaça imediata, exibe suas armas para fora da viatura, como se o bairro popular fosse uma zona de guerra permanente.

Estabelecer um conceito de bairro popular também foi uma necessidade diante da profusão de denominações regionais, a exemplo de favela, vila, avenida, mocambo, invasão, somando-se às resistências de algumas correntes em pesquisar o intra-urbano, devido ao seu poder de induzir estudos fragmentadores da cidade; ou ainda, pelo fato de existir autores que, por ter uma visão de bairro condicionada às áreas que se enquadram em normas urbanísticas rígidas, não reconhecem os bairros populares das cidades brasileiras, principalmente das metrópoles, como compatíveis com suas conceituações de bairro.

Dialoguei com muitos autores de posições diferenciadas, estabeleci uma tensão com Jacobs (2003) e Harvey (2004), embora sejam autores que influenciaram e influenciam a minha formação, mesmo tendo grandes diferenças entre si, e desenvolveram uma proposta conceitual que não incorpora os bairros populares americanos. Tensão que foi estendida para Souza $(2002,2013)$ quando este autor trilha o mesmo percurso e propõe a "fragmentação do tecido sociopolítico-espacial da cidade" para as favelas do Rio de Janeiro dominadas por tráfico e milícias.

Ora, a ausência do Estado, a presença beligerante da polícia e a violência do tráfico não são ações que ocorrem sem a resistência da população através da reprodução da própria vida cotidiana, fundada em relações de parentesco e vizinhança, relações estas que vão de encontro a essas ações, forjando identidades e pertencimentos territoriais muito fortes. Claudia Santos (2009), em pesquisa no Nordeste de Amaralina, um dos bairros populares mais violentos de Salvador, registra que a totalidade dos moradores ou não pretendiam sair dali ou, se saíssem, sairiam para outro bairro popular. Júnior (2006) vai ao encontro da mesma constatação ao pesquisar bairros populares do Rio de Janeiro. Então, é bastante questionável a ideia totalizante de que todo habitante de bairros populares só mora nesses lugares porque não tem outra alternativa.

A proposição de bairro popular defendida em Dias (2017), e que reafirmo aqui, tem influências das pesquisas de Serpa (2002, 2009, 2011), 
Valladares (1981, 1991, 2000, 2001, 2005) e Vianna (1980), mas busquei formular algo com contornos mais definidos pela necessidade de circunscrever melhor o objeto da pesquisa de doutorado. Na tese, afirmo que:

\begin{abstract}
O bairro popular em Salvador, ou, como possibilidade, para as grandes cidades brasileiras, é um lugar que só pode ser compreendido através de seus múltiplos aspectos como violência, carências materiais, pobreza, habitações precárias para uma boa parte de seus habitantes, e, ao mesmo tempo, como um lugar de resistência que se gesta em um cotidiano de vizinhança e de parentesco, de ajuda mútua, que também tem intensidades diferentes a depender da formação, sem, contudo, se negar a existência de conflitos entre vizinhos e a violência domiciliar contra as mulheres e as crianças, porém as ações solidárias superam estes conflitos e violências. Os bairros populares são lugares que apresentam expressiva diversidade em termos de renda, condições das moradias, atendimento pelos serviços públicos, regulamentações destes serviços, mas também, diferente das formações com população de renda mais elevada, um cotidiano que estrutura resistências contra as verticalidades (DIAS, 2017, p. 71).
\end{abstract}

\title{
2. 0 bairro popular na grande cidade: o lugar da transformação?
}

A potência dos pobres dos espaços metropolitanos advém de uma intensa comunicação que escapa ao controle do território normado e pelo fato de que a população local conta com acesso precário ao meio técnico-científico-informacional. A cidadania, por não ter sido uma etapa do seu processo de formação histórica, provoca seu encontro com a globalização como consumidor mais que perfeito, que é um cidadão imperfeito. Isso cria uma necessidade de sobrevivência que resulta em uma profícua comunicação e que aponta, na maioria das vezes, para um futuro alternativo (SANTOS, 1990, 1996, 1997, 1998, 1999, 2000a, 2000b, 2002; SANTOS; SILVEIRA, 2001).

Propus o bairro como o lugar privilegiado de uma comunicação específica/especial, embora reconhecendo os espaços coletivos comuns como importantes, porque trazem um componente diferenciado dos espaços coletivos da cidade, como parques, estações de ônibus, metrô, modais náuticos, estádios de futebol, praias e outros. Lugares nos quais as relações entre os pobres são mais marcadas pelo anonimato, enquanto nos bairros populares são dominadas pelas relações de vizinhança e/ou parentesco que favorecem muito um cotidiano mais compartilhado e profundo. 
Outro aspecto muito importante que deve ser associado ao fato de o espaço geográfico ser uma instância da análise social, é que Milton Santos (1999, 2000a), ao dar o protagonismo ao pobre sem diferenciá-lo em categorias internas, propõe uma nova dinâmica àquilo que a Escola de Frankfurt nomeou de cultura de massas. A cultura de massas em Milton Santos continuaria a mercantilizar e tornar sem sentido uma grande parte da produção da cultura popular, mas, diferentemente dos teóricos de Frankfurt, propõe que a renovação da cultura popular, no período atual, é tão intensa pelo papel que desempenham os pobres das grandes cidades. Para o autor, a cultura de massas não tem condições de absorver a velocidade da renovação da cultura popular. E nas pesquisas por mim realizadas (DIAS, 2002, 2017) identifiquei o bairro popular como o lugar potencializador e fermentador desta cultura.

Em pesquisa sobre o Carnaval de Salvador, no final dos anos 1990 e início dos anos 2000 (DIAS, 2002), constatei que os blocos populares e afoxés, embora se apresentem nas áreas centrais da cidade, têm sua formação nos bairros populares, onde o processo de comunicação dos pobres se baseia em intensas relações de vizinhança e parentesco e um cotidiano diferenciado dos bairros de maiores rendas, nos quais seus habitantes têm acesso mais pleno ao meio técnico-científico-informacional. Nos bairros populares são elaborados ritmos musicais muito variados por miríades de artistas anônimos que não podem ser capturados pela cultura de massas devido à grande quantidade de produção. E, assim como Santos (1997) se refere à revanche do território, pode-se tomar emprestado o termo e falar da revanche da cultura popular, a partir dos bairros populares.

A teoria social identifica, desde que as grandes cidades se formaram no Brasil, os grandes contingentes de migrantes na formação das metrópoles. O migrante pobre, por ser considerado um "desterritorializado" que busca a sobrevivência em um lugar desconhecido, sempre foi considerado um grupo secundário pela análise social. Milton Santos problematiza semelhantes interpretações e coloca o migrante em posição de destaque, ao propor que a própria fragilidade seja transformada em força, na medida em que o migrante tem um forte desejo de entender o espaço que o cerca, transformando-se em um ser que não naturaliza o lugar e busca sentido em cada objeto e em cada ação. 
O conjunto da teoria miltoniana orientou a pesquisa em que propus o bairro popular como o lugar da grande cidade onde a comunicação dos pobres se realiza com maior intensidade, em razão das relações de vizinhança e parentesco existentes nos referidos espaços. A pesquisa foi realizada em três aglomerados de bairros, por sua vez, definidos como um conjunto de bairros que possuem história e cotidiano em comum e no qual as populações se reconhecem como habitantes de uma formação geográfica que é intermediária entre o bairro e a cidade. Os aglomerados Nordeste de Amaralina (04 bairros), Subúrbio Ferroviário (17 bairros) e Cajazeiras (15 bairros), além do bairro da Paz, foram selecionados por critérios como tempo de formação histórica diferenciado, distâncias para as áreas centrais da cidade, por possuírem populações expressivas e por apresentarem forte significado na composição da cidade.

As práticas observadas de parentesco e vizinhança foram dezenas, em ambientes que têm uma violência crônica já mencionada. Encontrou-se, em todas as formações, conhecidas práticas de mutirão para a construção de casas, mas também mutirões para reparos ou aberturas de ruas no início das ocupações em algumas áreas. Foi possível enxergar crianças transformando ruas sem movimentação de veículos, em espaços de brincadeira, em razão da falta de espaço em seus domicílios e, em alguns momentos, certos comandantes da polícia ir até os canais de mídias regionais para falar que a presença de crianças nas ruas era uma forma de os traficantes usá-las para atrapalhar a movimentação policial.

É comum que um adulto ou adolescente de uma rua busque os filhos de vizinhos na escola. Quando a falta das creches era muito mais grave do que agora, era e ainda é comum mulheres tomarem conta dos filhos de outras, em troca de algum pagamento simbólico gerando relações criadoras de afetos entre moradores.

Entre as práticas observadas podemos mencionar: donos de automóveis que utilizam o seu carro para levar pessoas em estado de emergência ao hospital; times de futebol que fazem partidas de campeonatos organizados no final de semana; a compra com base no fiado em algumas vendas e até em mercadinhos maiores; festas de bairro como o Carnaval, São João e Iemanjá; grupos de vizinhos que trocam serviços de eletricidade, encanamento, 
pintura; grupos de WhatsApp que funcionam como rede de proteção contra os surtos de violência de rua na proteção, principalmente, das crianças.

Ou ainda: caronas de automóveis de residentes nas entradas dos bairros, em finais-de-linha de ônibus para pessoas com carências reconhecidas pelos motoristas, cooperativas informais de carros particulares que fazem transporte em trajetos sem cobertura de linhas regulares, colheita de frutas por parentes e vizinhos no Parque da Cidade, serviços de motoboy a crédito e tantas outras práticas que se torna desnecessário listá-las todas aqui.

\section{Em direção ao futuro}

O importante a se reter é que o conjunto das práticas citadas se apresenta como o fator de resistência de um cotidiano que garante a existência dos bairros populares em uma realidade marcada por tensões e carências de várias ordens, mas que, ao mesmo tempo, tem, nas redes de comunicação e solidariedade entre vizinhos, a possibilidade de enxergar o futuro. Redes que podem se exprimir tanto através de organizações formais como associações de bairros, grupos culturais e Organizações Não Governamentais (ONGs) com variados objetivos, ou, como na maioria das vezes, se expressarem através de variadas práticas autônomas, como as que foram citadas. Práticas que se renovam, desaparecem ou aparecem como novas, em uma dinâmica regulada pela necessidade dos pobres.

Outro ponto que se considera muito importante é o fato de essas práticas não serem restritas à cidade de Salvador, mas também serem observadas por vários autores em pesquisas realizadas em bairros populares do Rio de Janeiro, São Paulo, em várias grandes cidades brasileiras e também em cidades africanas. E a comunicação diferenciada dos pobres ocorre quando não se incorpora ao conjunto da lógica da comunicação do meio técnico-científico-informacional, seja através de um grupo de dança, música, trabalho, esporte, ou de grupos de colegas de escola. Cada um desses grupos estabelece uma rede de proteção à violência interna desses bairros, à ausência do Estado e às verticalidades da globalização.

Admitindo a proposição miltoniana de que dois períodos históricos convivem na atualidade, o período dominado pela globalização e pelo meio 
técnico-científico-informacional, que são hegemônicos, e, do outro lado, o período demográfico da história, como expressão de oposição àquele, é preciso incorporar o espaço geográfico como uma das instâncias da análise social para se compreender essa simultaneidade complexa; na medida em que a identificação dos períodos, tanto do meio técnico-científico-informacional, quanto do Período Popular da História, necessita de conceitos geográficos como território, região, lugar e todo conjunto conceitual da geografia.

E a pesquisa geográfica sobre o cotidiano dos pobres que habitam os bairros populares, nas grandes cidades brasileiras, é uma possiblidade de caminho da pesquisa geográfica no entendimento das manifestações e ações da globalização e do seu contraponto: a comunicação dos pobres.

\section{Referências}

CASTORIADIS, C. Encruzilhadas do Labirinto. Rio de Janeiro: Paz \&Terra, 1987.

DIAS, C. Carnaval de Salvador: mercantilização e produção de espaços de segregação, exclusão e conflito. 2002. 195f. Dissertação (Mestrado em Geografia) - Instituto de Geociências, Universidade Federal da Bahia, Salvador, 2002.

DIAS, C. Práticas Socioespaciais e Processos de Resistência na Grande Cidade: relações de solidariedade nos bairros populares de Salvador. 2017. 285f. Tese (Doutorado em Geografia) - Instituto de Geociências, Universidade Federal da Bahia, Salvador, 2017.

HABERMAS, J. Teoria do Agir Comunicativo. Vol. I. São Paulo: Martins Fontes, 2011. HARVEY, D. Espaços de Esperança. São Paulo: Loyola, 2004.

JACOBS, J. Morte e Vida de Grandes Cidades. São Paulo: Martins Fontes, 2003. JÚNIOR, J. Da Favela para o Mundo: a história do grupo cultural Afro Reggae. Rio de Janeiro: Ediouro, 2006.

MARX, K; ENGELS, F. O Manifesto Comunista. Fonte Digital. Rocketedition de 1999 a partir de html em www.jahr.org. Disponível em http://www.ebooksbrasil. org/adobeebook/manifestocomunista.pdf. Acesso em 2015.

RECLUS, E. A Evolução, a Revolução e o Ideal Anarquista. Rio de Janeiro: Editora Imaginário, 2011.

RECLUS, E. O Homem e a Terra: educação. Rio de Janeiro: Editora Imaginário, 2010. 
SANTOS, C. A Violência no contexto dos espaços vividos, percebidos e concebidos na cidade de Salvador: estudo do caso nos bairros da Pituba e Nordeste de Amaralina. 2009. 138f. Dissertação (Mestrado em Geografia) Instituto de Geociências, Universidade Federal da Bahia, Salvador, 2009.

SANTOS, M. A Natureza do Espaço: técnica e tempo, razão e emoção. 3. ed. São Paulo: Hucitec, 1999.

SANTOS, M. Metamorfoses do Espaço Habitado. 5. ed. São Paulo: Hucitec, 1997.

SANTOS, M. Metrópole Corporativa Fragmentada: o caso de São Paulo. São Paulo: Nobel, 1990.

SANTOS, M. O Espaço do Cidadão. 3. ed. São Paulo: Nobel, 1996.

SANTOS, M. Pobreza Urbana. São Paulo: Edusp, 2009.

SANTOS, M. Por uma outra Globalização. São Paulo: Record, 2000a.

SANTOS, M. Técnica, Espaço e Tempo: globalização e meio técnico-científico informacional. 4. ed. São Paulo: Hucitec, 1998.

SANTOS, M. Território e Sociedade: entrevista com Milton Santos. São Paulo: Editora da Fundação Perseu Abramo, 2000b.

SANTOS, M. Testamento Intelectual. São Paulo: Unesp, 2002.

SANTOS, M.; SILVEIRA, M. L. O Brasil: território e sociedade no início do século XXI. Rio de Janeiro/São Paulo: Record, 2001.

SARTRE, J. P. L' Exitentialisme est un Humanisme. Paris: Les Éditions Nagel, 1970.

SERPA, A. Ativismos Socioculturais nos Bairros Populares de Salvador: relações entre cultura e política na articulação de novos conteúdos para a esfera pública urbana. Cidades, São Paulo, v. 6, n. 9, 2009.

SERPA, A. Lugar e Mídia. São Paulo: Contexto, 2011.

SERPA, A. Margens de Salvador: A produção do espaço periférico metropolitano. In: LIMA, P. C.; LUZ, A. M. de C.; CARVALHO, M. J. de; SERRA, O. (Org.). Quem Faz Salvador? Salvador: UFBA-Pró-Reitoria de Extensão/Prefeitura Municipal de Salvador, 2002. p. 295-303.

SOUZA, M.L. Mudar a Cidade. Rio de Janeiro: Bertrand Brasil, 2002.

SOUZA, M. L. Os Conceitos Fundamentais da Pesquisa Sócio Espacial. Rio de Janeiro: Bertrand Brasil, 2013. 
VALLADARES, L.P. A gênese da favela carioca: a produção anterior às ciências sociais. Revista Brasileira de Ciências Sociais, Rio de Janeiro, v. 15, n. 44 , p. 5-34, 2000.

VALLADARES, L. P. A invenção da favela: do mito de origem da favela. Rio de Janeiro: FGV, 2005.

VALLADARES, L. P. A propósito da urbanização de favela. Espaço e Debates, São Paulo, v. 1, n. 2, p. 5-18, 1981.

VALLADARES, L. P. Cem anos pensando a pobreza (urbana) no Brasil. In: BOSCHI, R. (Org.). Corporativismo e desigualdade: a construção do espaço público no Brasil. Rio de Janeiro: IUPERJ, Rio Fundo, 1991. p. 81-122.

VALLADARES, L. P. Favela.com. In: FORUM AMERICA LATINA HABITAR 2000, Salvador, 2001. Anais... Salvador, 2001.

VIANNA, A. R. Estratégias de Sobrevivência em um Bairro pobre de Salvador. Petrópolis: Vozes-CEBRAP, 1980.

Recebido em: 26/10/2021

Aceito em: 05/11/2021 